\title{
reviews
}

Gordon PASK has always been something of an enigma on the educational and psychological scene. Operation from a private research company, although common in the States, is still a source of puzzlement in Britain. For many years Pask remained outside any comprehensible 'establishment' with a reputation and stature that developed, and was recognised, far more outside his own country than within it. His diversity of interests, from deep epistenological problems and system theory to practical training and the construction of elaborate electomechanical automata exhibiting "learning' or inducing training, have also made him difficult to place. His writings* make few concessions to the reader, rarely simplifying what Pask already regards as an oversimplified view of a very complex world, and expressing it in a wide vocabulary appropriate to the richness and breadth of his conception of that world. Although one may admire an attempt to face up to a major part of the world of human acquisition of knowledge in its own terms, one may, however, also question its timeliness with regard to the intellectual and computational tools currently available to us.

Although there are few nowadays who would question the depth or logical consistency of Pask's approach, there may be many who will question its wisdom. The history of science is full of premature attempts to consolidate major areas of knowledge, before the correct viewpoint, reasonable objectives, or appropriate logicomathematical tools have been established. Pask adopts the all-embracing methodologies of Wiener's cybernetics and Bertalannfy's general systems theory and applies them to the highest levels of human behaviour and to practical problems of teaching and training. To what extent is he successful? I cannot give a clear-cut answer to this question. Neither will I pretend that the answer lies in this one book. What is clear, however, from grappling with the material in this book, both in its original form (as published papers) and in its present integrated form, is that the questions of 'success' cannot be answered negatively.

*Conversation, Cognition and Learning: A Cybernetic Theory and Methodology. By Gordon Pask. Pp. xi +570 . (Elsevier: Amsterdam, Oxford and New York, 1975.) Dfl.96; \$36.95.

\section{Common sense and the computer}

"'Pask has put much effort into the development of actual teaching systems for major subject areas .... and the practical experience and exemplary material developed is used to give life and content to the abstract, theoretical concepts put forward ... No-one who takes the trouble to immerse himself in the work can fail to gain from the experience."

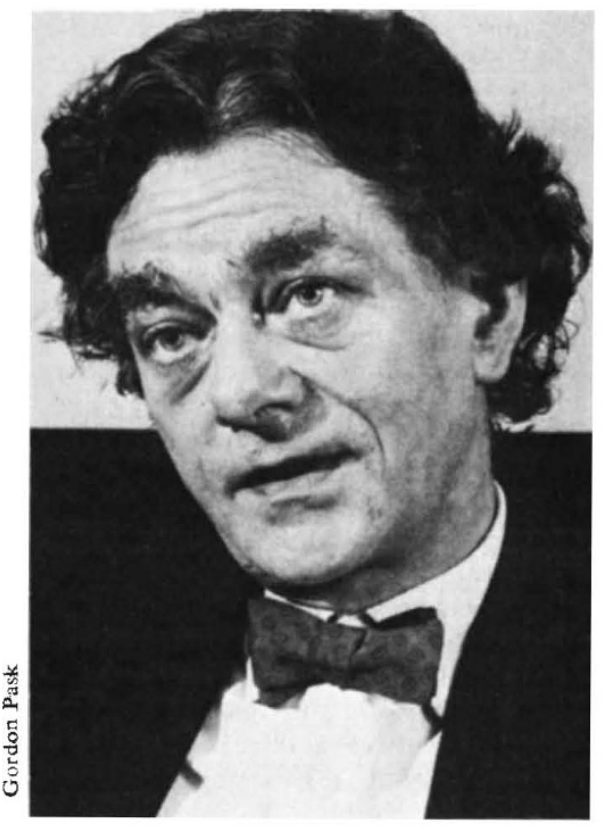

Pask has put much effort into the development of actual teaching systems for major subject areas, such as probability theory and statistics, and the practical experience and exemplary material developed is used to give life and content to the abstract, theoretical concepts put forward. There is a healthy atmosphere of operationalism throughout the work that convinces one that the cybernetic terminology is significant and applicable. No-one who takes the trouble to immerse himself in the work can fail to gain from the experience-Pask teases at basic problems from many directions at many levels and the discussion throughout is highly stimulating.

Although psychologists and system theorists will find the book of interest, its most immediate contribution is probably to studies of computer-based instruction (CAI). Pask's own use of the computer is slight-indeed, perhaps much of the insight he gives is because his structures are natural ones not distorted to fit a standard 'flow-chart' or use the keyboard of a teleprinter! His discussion of the learning and training strategies appropriate to the 'serialist' and 'holist' thinking on the one hand, and his demonstration of the complex entailment structures of comparatively simple subject areas on the other, illu- minate major problems of CAI (and other forms of programmed instruction).

There is a paradox in our ability to develop teaching systems that work quite well for a wide range of individuals, whereas we know that there is a massive variation in student's tutorial requirements. Pask shows how performance feedback in adaptive teaching systems can tailor tuition to the individual without requiring detailed identification of his traits, provided broad differences in learning strategies can be recognised and the structure of the subject area has been thoroughly analysed. To the practising teacher such insights may seem common sense but no-one has so far successfully incorporated the common sense of the human teacher in a computer program. It is fundamental work, such as that described by Pask, that is essential if this is to become a reasonable objective.

The evaluation of Pask's work must be left to posterity - one hopes that this book will have several successors, developing and elucidating his theories and techniques. The present work must be welcomed as an onportunity to analyse, evaluate and utilise a substantial body of original and stimulating psychological and educational research.

B. R. Gaines 